\title{
Comprehensive Analysis of the Prognosis of S100 Family Members and Their Relationship with Tumor- Infiltrating Immune Cells in Human Pancreatic Adenocarcinoma
}

\section{Yajun Ren \\ The First Affiliated Hospital of Zhengzhou University \\ Bing Chen \\ The First Affiliated Hospital of Zhengzhou University \\ Meng Zhang \\ The First Affiliated Hospital of Zhengzhou University \\ Feng Xu ( $\nabla$ xufengmd@sina.com) \\ The First Affiliated Hospital of Zhengzhou University}

\section{Research Article}

Keywords: Pancreatic Adenocarcinoma, S100s, Comprehensive Analysis, Prognosis, Immune Infiltration

Posted Date: February 23rd, 2022

DOI: https://doi.org/10.21203/rs.3.rs-841869/v2

License: (c) (1) This work is licensed under a Creative Commons Attribution 4.0 International License.

Read Full License 


\section{Abstract}

Background: S100 family members(S100s) are small molecular EF hand calcium binding proteins and widely expressed in many tissues and organs. S100s are shown to be biomarkers of disease progression and prognosis in various types of cancers. Nevertheless, the expression patterns, function, prognostic values of S100s and its association with tumor-infiltrating immune cells in Pancreatic Adenocarcinoma(PAAD) patients have not been systematically clarified.

Methods: we explored that the expression and roles of the entire twenty S100s in PAAD patients by using the following public databases: Oncomine, GEPIA, cBioPortal, Metascape, STRING, TIMER and GeneMANIA.

Results: The S100A2/A3/A4/A6/A8/A9/A10/A11/A13/A14/A16/B/P mRNA expression were significantly upregulated in PAAD patients. The mRNA expression of S100A3/A4/A5/A6/A10/A11/A14/A16/Z were significantly negatively related with the tumor stage in PAAD patients. We found that the S100A2/A3/A5/A10/A11/A14/A16 were significantly correlated with poor OS, whereas the increased levels of $S 100 A 1 / B / G / Z$ were strongly associated with good OS. We found significant correlations among S100s and Tumor-Infiltrating Immune Cells. Cox proportional risk models revealed that B cells, Dendritic cells and S100A1/A5/A6/A8/A9/A13/A14 were significantly related with outcomes in PAAD patients.

Conclusions: S100A2/A3/A10/A11/A14/A16 may serve as new diagnostic and prognostic biomarkers for PAAD patients and provide new clues for immunotherapy in PAAD patients.

\section{Background}

Pancreatic Adenocarcinoma(PAAD) always cause high lethality in patients, and the incidence of PAAD has increased over the past few decades and it is likely to continue to increase further ${ }^{1,2}$. It is predicted that by 2030, the number of deaths from PAAD will dramatically increase and become the second most common cause of death from cancers ${ }^{3}$. Hence, there is a need to look for reliable predictive biomarkers and accurate outcomes of PAAD patients.

S100 family members(S100s) are small molecular EF hand calcium binding proteins and that are widely expressed in many tissue organs and play important roles in many biological processes, including Calcium homeostasis, inflammation, proliferation, differentiation, cell migration, apoptosis and so on ${ }^{4}$.

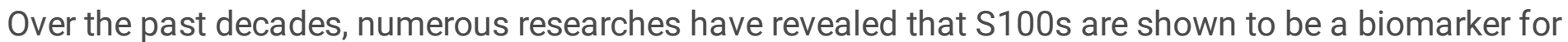
disease progression and prognosis in different types of cancers, for instance, lung cancer ${ }^{5}$, acute myeloid leukemia ${ }^{6}$, melanoma ${ }^{7}$, ovarian cancer ${ }^{8,9}$, breast cancer ${ }^{10}$, and so on. The aberrant expression of S100s and its correlation with prognosis and pathological features have been partially reported in PAAD patients. Several studies have suggested that S100A4 may serve as a possible biomarker, because of its expression was correlated with malignancy, metastasis, invasion and poor OS in PAAD ${ }^{11,12}$. The higher 
expression of S100A2 was associated with progression, and predicts a good response to pancreatectomy in PAAD ${ }^{13,14}$. S100A6, S100A11 and S100P may also be useful biomarkers for the diagnosis in PAAD patients ${ }^{15,16}$. However, the functions of other S100s in PAAD have not yet been completely elucidated.

As far as we know, there have not been use systematical bioinformatics analysis to investigate the expression of the entire twenty S100s and associations with tumor immunity in PAAD patients. In recent years, microarray and RNA-seq technology has developed very quickly ${ }^{17}$, in our study, we used the different databases to analyze the expression patterns, mutations, functional networks and correlations with tumor stage, outcomes and Tumor-Infiltrating Immune Cells in PAAD patients.

\section{Methods}

\section{Oncomine}

The Oncomine is an integrated online microarray database ${ }^{18}$. In our research, we contrasted the $S 100$ s mRNA expression of tumor tissues with that of normal tissues in various cancers, and $p$ value was generated by Student's- $t$ test, with $p$ value $<0.01$, fold change $\geq 2$, data type: mRNA, gene bank: $10 \%$.

\section{GEPIA 2}

The GEPIA 2 datasetsis an easy-to-use online tool and used to analyze the RNA-seq results from the TCGA and GTEx projects, containing 8587 normal and 9736 tumors samples $^{19}$. In our research, we performed the S100s mRNA expression analysis, tumor stage analysis, Overall survival(OS), Disease-free survival(DFS) by using GEPIA 2. The threshold of $p$ value was 0.05 . The expression and tumor stage analysis were evaluated using the Student's $t$-test. OS and DFS were evaluated using Kaplan-Meier method.

\section{TCGA and cBioPortal}

TCGA database contain RNA-seq data and clinicopathologic information for thirty various cancers ${ }^{20}$. In our study, we used the cBioPortal ${ }^{21,22}$ to perform the $\$ 100$ s genomics profiles analysis of the Pancreatic Adenocarcinoma(TCGA, Firehose Legacy) dataset, including 186 cases, including mutations, Putative copy-number alterations from GISTIC, mRNA Expression z-Scores (threshold: \pm 2.0 ) and Protein expression Z-scores (threshold: \pm 2.0 ). In addition, we conduct the co-expression analysis and correlation analysis among the genetic mutations of S100s with OS and DFS by using the cBioPortal.

\section{GeneMANIA}

The GeneMANIA is a online tool and provides some information, including protein-protein and gene-gene interactions, protein domain similarity, co-localization, co-expression, pathways, and so on ${ }^{23}$. In our study, we used GeneMANIA to find neighboring genes which were significantly related with S100s by performing 
the pathway enrichment and functional annotation analysis, and then construct a gene-gene interaction network.

\section{STRING}

The STRING is a friendly website and used to predict the protein-protein interaction(PPI ${ }^{24}$. In our study, we constructed a PPI network of S100s by using STRING.

\section{Metascape}

The Metascape is a friendly website for exploring GO enrichment analysis and KEGG enrichment analysis ${ }^{23}$. In our research, we analyzed the gene annotation and pathway enrichment analysis of S100s and neighboring genes by using the Metascape. The thresholds of $p$ value, Min Overlap and Min Enrichment were limited as $0.01,3$ and 1.5, respectively.

\section{TIMER 2.0}

The TIMER 2.0 is a very convenient and practical website for

exploring the correlations between tumor-infiltrating immune cells and their effects on clinical prognosis ${ }^{25,26}$. In our research, we used the TMIER 2.0 to investigate the relationship of S100s expression with tumor-infiltrating immune cells and clinical outcomes in PAAD patients by Cox proportional hazard model.

\section{Results}

\section{The S100s mRNA expression in PAAD patients}

We compared the S100s mRNA expression in different types of cancers with normal tissues. S100s, such as S100A1, S100A2, S100A3, S100A4, S100A5, S100A6, S100A7, S100A7A, S100A8, S100A9, S100A10, S100A11, S100A12, S100A13, S100A14, S100A16, S100B, S100G, S100P and S100Z were explored in human multiple cancers in Oncomine(Fig. 1 and Table 1). The databases included 349, 335, 342, 309, $300,243,320,153,344,326,352,314,344,343,248,171,362,296,344,147$ unique analyses for S100A1-S100Z, respectively. The mRNA expressions of S100s were significantly altered in a majority of human cancers, including upregulated and downregulated. The mRNA expression of S100A2/A4/A6/A10/A11/A13/A14/A16/P were overexpressed in PAAD patients. The other S100s were not significantly difference in PAAD and normal tissues.

As it shown in Table 1, in Pei's dataset, S100A2/A4/A6/A10/A11/A14/A16/P were overexpressed in PAAD tissue with a fold change of 7.68, 4.857, 9.149, 3.537, 4.953, 6.455, 4.396 and 77.931, respectively. lacobuzio-Donahue's dataset, S100A2/A10/A11/A13/P were up-regulated in PAAD tissue with a fold change of $3.613,5.514,7.198,2.225$ and 24.015 , respectively. Logsdon et al. showed that 
S100A4/A10/A11/A13/P were increased in PAAD tissue(fold change: 4.442, 7.578, 18.29, 7.197 and 20.309, respectively). Badea et al. shown that the higher levels of S100A4/A6/A10/A11/A13/A16/P were found in PAAD tissue(fold change: 4.374, 5.919, 3.095, 4.43, 2.186, 2.327 and 13.177, respectively). Segara et al. showed that S100A6/A10/A11/A13/P were found higher expressed in PAAD tissue with a fold change of $4.764,4.299,7.519,2.68$ and 17.727, respectively. Grutzmann et al. found that the expression of S100A16 (fold change $=2.36$ ) and S100P (fold change $=8.382$ ) were raised in PAAD tissue versus normal tissues. Buchholz et al. reported that S100A16 was over-expressed in PAAD tissue(fold change $=2.162$ ). Ishikawa et al. reported that S100P (fold change $=4.247$ ) was higher expressed in PAAD patients. 
Table 1

The significant change of S100s mRNA expression in PAAD patients(Oncomine)

\begin{tabular}{|c|c|c|c|c|c|c|}
\hline & $\begin{array}{l}\text { Type of Pancreatic } \\
\text { Cancer vs. Normal }\end{array}$ & $\begin{array}{l}\text { Fold } \\
\text { Change }\end{array}$ & $\begin{array}{l}p \\
\text { value }\end{array}$ & $t$ Test & References & PMID \\
\hline \multirow[t]{2}{*}{ S100A2 } & Pancreatic Carcinoma & 7.68 & $\begin{array}{l}2.97 \mathrm{E}- \\
08\end{array}$ & 6.379 & Pei Pancreas & 19732725 \\
\hline & $\begin{array}{l}\text { Pancreatic } \\
\text { Adenocarcinoma }\end{array}$ & 3.613 & $\begin{array}{l}6.00 \mathrm{E}- \\
03\end{array}$ & 2.936 & $\begin{array}{l}\text { lacobuzio- } \\
\text { Donahue } \\
\text { Pancreas } 2\end{array}$ & 12651607 \\
\hline \multirow[t]{3}{*}{ S100A4 } & $\begin{array}{l}\text { Pancreatic } \\
\text { Adenocarcinoma }\end{array}$ & 4.442 & $\begin{array}{l}6.52 \mathrm{E}- \\
05\end{array}$ & 5.738 & $\begin{array}{l}\text { Logsdon } \\
\text { Pancreas }\end{array}$ & 12750293 \\
\hline & $\begin{array}{l}\text { Pancreatic Ductal } \\
\text { Adenocarcinoma }\end{array}$ & 4.374 & $\begin{array}{l}1.54 \mathrm{E}- \\
10\end{array}$ & 7.614 & Badea Pancreas & 19260470 \\
\hline & Pancreatic Carcinoma & 4.857 & $\begin{array}{l}3.49 \mathrm{E}- \\
06\end{array}$ & 5.569 & Pei Pancreas & 19732725 \\
\hline \multirow[t]{3}{*}{ S100A6 } & Pancreatic Carcinoma & 9.149 & $\begin{array}{l}4.98 \mathrm{E}- \\
12\end{array}$ & 9.154 & Pei Pancreas & 19732725 \\
\hline & $\begin{array}{l}\text { Pancreatic Ductal } \\
\text { Adenocarcinoma }\end{array}$ & 5.919 & $\begin{array}{l}1.32 \mathrm{E}- \\
12\end{array}$ & 9.024 & Badea Pancreas & 19260470 \\
\hline & Pancreatic Carcinoma & 4.764 & $\begin{array}{l}2.31 \mathrm{E}- \\
04\end{array}$ & 4.842 & $\begin{array}{l}\text { Segara } \\
\text { Pancreas }\end{array}$ & 15867264 \\
\hline \multirow[t]{5}{*}{ S100A10 } & Pancreatic Carcinoma & 4.299 & $\begin{array}{l}8.32 \mathrm{E}- \\
07\end{array}$ & 8.149 & $\begin{array}{l}\text { Segara } \\
\text { Pancreas }\end{array}$ & 15867264 \\
\hline & $\begin{array}{l}\text { Pancreatic } \\
\text { Adenocarcinoma }\end{array}$ & 7.578 & $\begin{array}{l}2.79 \mathrm{E}- \\
06\end{array}$ & 10.075 & $\begin{array}{l}\text { Logsdon } \\
\text { Pancreas }\end{array}$ & 12750293 \\
\hline & $\begin{array}{l}\text { Pancreatic Ductal } \\
\text { Adenocarcinoma }\end{array}$ & 3.095 & $\begin{array}{l}1.31 \mathrm{E}- \\
11\end{array}$ & 8.377 & Badea Pancreas & 19260470 \\
\hline & $\begin{array}{l}\text { Pancreatic } \\
\text { Adenocarcinoma }\end{array}$ & 5.541 & $\begin{array}{l}7.36 \mathrm{E}- \\
04\end{array}$ & 6.074 & $\begin{array}{l}\text { lacobuzio- } \\
\text { Donahue } \\
\text { Pancreas } 2\end{array}$ & 12651607 \\
\hline & Pancreatic Carcinoma & 3.537 & $\begin{array}{l}2.05 \mathrm{E}- \\
06\end{array}$ & 6.056 & Pei Pancreas & 19732725 \\
\hline \multirow[t]{3}{*}{ S100A11 } & Pancreatic Carcinoma & 7.519 & $\begin{array}{l}7.48 \mathrm{E}- \\
07\end{array}$ & 7.646 & $\begin{array}{l}\text { Segara } \\
\text { Pancreas }\end{array}$ & 15867264 \\
\hline & $\begin{array}{l}\text { Pancreatic Ductal } \\
\text { Adenocarcinoma }\end{array}$ & 4.43 & $\begin{array}{l}1.19 \mathrm{E}- \\
14\end{array}$ & 10.448 & Badea Pancreas & 19260470 \\
\hline & $\begin{array}{l}\text { Pancreatic } \\
\text { Adenocarcinoma }\end{array}$ & 18.29 & $\begin{array}{l}9.25 \mathrm{E}- \\
05\end{array}$ & 10.081 & $\begin{array}{l}\text { Logsdon } \\
\text { Pancreas }\end{array}$ & 12750293 \\
\hline
\end{tabular}




\begin{tabular}{|c|c|c|c|c|c|c|}
\hline & $\begin{array}{l}\text { Type of Pancreatic } \\
\text { Cancer vs. Normal }\end{array}$ & $\begin{array}{l}\text { Fold } \\
\text { Change }\end{array}$ & $\stackrel{p}{\text { value }}$ & $t$ Test & References & PMID \\
\hline & $\begin{array}{l}\text { Pancreatic } \\
\text { Adenocarcinoma }\end{array}$ & 7.198 & $\begin{array}{l}8.54 \mathrm{E}- \\
04\end{array}$ & 6.014 & $\begin{array}{l}\text { lacobuzio- } \\
\text { Donahue } \\
\text { Pancreas } 2\end{array}$ & 12651607 \\
\hline & Pancreatic Carcinoma & 4.953 & $\begin{array}{l}6.35 \mathrm{E}- \\
06\end{array}$ & 5.827 & Pei Pancreas & 19732725 \\
\hline \multirow[t]{4}{*}{ S100A13 } & Pancreatic Carcinoma & 2.68 & $\begin{array}{l}1.85 \mathrm{E}- \\
05\end{array}$ & 6.004 & $\begin{array}{l}\text { Segara } \\
\text { Pancreas }\end{array}$ & 15867264 \\
\hline & $\begin{array}{l}\text { Pancreatic } \\
\text { Adenocarcinoma }\end{array}$ & 7.197 & $\begin{array}{l}2.00 \mathrm{E}- \\
03\end{array}$ & 5.259 & $\begin{array}{l}\text { Logsdon } \\
\text { Pancreas }\end{array}$ & 12750293 \\
\hline & $\begin{array}{l}\text { Pancreatic Ductal } \\
\text { Adenocarcinoma }\end{array}$ & 2.186 & $\begin{array}{l}3.32 \mathrm{E}- \\
10\end{array}$ & 7.256 & Badea Pancreas & 19260470 \\
\hline & $\begin{array}{l}\text { Pancreatic } \\
\text { Adenocarcinoma }\end{array}$ & 2.225 & $\begin{array}{l}6.00 \mathrm{E}- \\
03\end{array}$ & 3.327 & $\begin{array}{l}\text { lacobuzio- } \\
\text { Donahue } \\
\text { Pancreas } 2\end{array}$ & 12651607 \\
\hline S100A14 & Pancreatic Carcinoma & 6.455 & $\begin{array}{l}4.85 \mathrm{E}- \\
07\end{array}$ & 6.496 & Pei Pancreas & 19732725 \\
\hline \multirow[t]{4}{*}{ S100A16 } & $\begin{array}{l}\text { Pancreatic Carcinoma } \\
\text { vs. Normal }\end{array}$ & 4.396 & $\begin{array}{l}9.46 \mathrm{E}- \\
08\end{array}$ & 7.263 & Pei Pancreas & 19732725 \\
\hline & $\begin{array}{l}\text { Pancreatic Ductal } \\
\text { Adenocarcinoma }\end{array}$ & 2.36 & $\begin{array}{l}7.00 \mathrm{E}- \\
03\end{array}$ & 2.678 & $\begin{array}{l}\text { Grutzmann } \\
\text { Pancreas }\end{array}$ & 15548371 \\
\hline & $\begin{array}{l}\text { Pancreatic Ductal } \\
\text { Adenocarcinoma }\end{array}$ & 2.327 & $\begin{array}{l}1.05 \mathrm{E}- \\
09\end{array}$ & 6.938 & Badea Pancreas & 19260470 \\
\hline & $\begin{array}{l}\text { Pancreatic Ductal } \\
\text { Adenocarcinoma }\end{array}$ & 2.162 & $\begin{array}{l}1.00 \mathrm{E}- \\
02\end{array}$ & 2.689 & $\begin{array}{l}\text { Buchholz } \\
\text { Pancreas }\end{array}$ & 16103885 \\
\hline \multirow[t]{6}{*}{ S100P } & $\begin{array}{l}\text { Pancreatic } \\
\text { Adenocarcinoma }\end{array}$ & 24.015 & $\begin{array}{l}2.13 \mathrm{E}- \\
08\end{array}$ & 11.298 & $\begin{array}{l}\text { lacobuzio- } \\
\text { Donahue } \\
\text { Pancreas } 2\end{array}$ & 12651607 \\
\hline & $\begin{array}{l}\text { Pancreatic } \\
\text { Adenocarcinoma }\end{array}$ & 20.309 & $\begin{array}{l}4.88 \mathrm{E}- \\
10\end{array}$ & 15.495 & $\begin{array}{l}\text { Logsdon } \\
\text { Pancreas }\end{array}$ & 12750293 \\
\hline & Pancreatic Carcinoma & 77.931 & $\begin{array}{l}1.61 \mathrm{E}- \\
12\end{array}$ & 10.194 & Pei Pancreas & 19732725 \\
\hline & Pancreatic Carcinoma & 17.727 & $\begin{array}{l}1.23 \mathrm{E}- \\
05\end{array}$ & 6.943 & $\begin{array}{l}\text { Segara } \\
\text { Pancreas }\end{array}$ & 15867264 \\
\hline & $\begin{array}{l}\text { Pancreatic Ductal } \\
\text { Adenocarcinoma }\end{array}$ & 4.247 & $\begin{array}{l}3.00 \mathrm{E}- \\
03\end{array}$ & 2.944 & $\begin{array}{l}\text { Ishikawa } \\
\text { Pancreas }\end{array}$ & 16053509 \\
\hline & $\begin{array}{l}\text { Pancreatic Ductal } \\
\text { Adenocarcinoma }\end{array}$ & 13.177 & $\begin{array}{l}8.53 \mathrm{E}- \\
13\end{array}$ & 8.437 & Badea Pancreas & 19260470 \\
\hline
\end{tabular}




\begin{tabular}{|c|c|c|c|c|c|}
\hline $\begin{array}{l}\text { Type of Pancreatic } \\
\text { Cancer vs. Normal }\end{array}$ & $\begin{array}{l}\text { Fold } \\
\text { Change }\end{array}$ & $\underset{\text { value }}{p}$ & $t$ Test & References & PMID \\
\hline $\begin{array}{l}\text { Pancreatic Ductal } \\
\text { Adenocarcinoma }\end{array}$ & 8.382 & $\begin{array}{l}8.00 \mathrm{E}- \\
03\end{array}$ & 2.703 & $\begin{array}{l}\text { Grutzmann } \\
\text { Pancreas }\end{array}$ & 15548371 \\
\hline
\end{tabular}

\section{The expression of S100s and their association with the tumor stage in PAAD patients}

We compared the S100s mRNA expression of PAAD tissues with control tissues by using GEPIA 2(Fig. 2). We found that the S100A2/A3/A4/A6/A8/A9/A10/A11/A13/A14/A16/B/P mRNA expression were significantly higher in PAAD, however, the other S100s mRNA expression were not significantly changed in PAAD tissues. we also used the GEPIA 2 dataset to analyze the S100s mRNA expression with pathological stage in PAAD patients. We found that the S100A3/A4/A5/A6/A10/A11/A14/A16/P/Z mRNA expression were significantly negatively associated with tumor stage of PAAD patients, whereas other S100s have not significantly difference (Fig. 3).

\section{Prognostic Values of S100s in PAAD patients}

Using GEPIA 2, we investigated the prognostic significance of S100s in PAAD patients. Interesting, the analysis revealed that higher expression of $\mathrm{S} 100 \mathrm{~A} 2 / \mathrm{A} 3 / \mathrm{A} 5 / \mathrm{A} 10 / \mathrm{A} 11 / \mathrm{A} 14 / \mathrm{A} 16$ were correlated with poor OS (Over Survival) significantly, whereas the increased level of S100A1/B/G/Z were strongly associated with good OS(Fig. 4). The other S100s were not correlated with OS in PAAD patients. In addition, the S100A2/A10 /A16 mRNA expression were predicted to have worse DFS(Disease-free survival), whereas the upregulated levels of S100A1/B were correlated with good DFS in PAAD patients(Fig. 5). The OS and DFS of S100A7A was not found in the GEPIA dataset. The other S100s were not correlated with DFS in PAAD patients.

\section{The genetic alteration of S100s in PAAD patients}

We explored the genetic alterations and its correlation in PAAD patients(TCGA, Firehose Legacy) by using cBioPortal. S100s were changed in 84 of 186 PAAD patients(45\%)(Fig. 6a). The genetic alterations of S100A14/A16/A10/A4 were the top four genes(14\%, $11 \%, 11 \%$ and $10 \%$, respectively). Furthermore, the further study found that PAAD patients with genetic alteration had shorter OS and DFS than those with nothing alterations, whereas there was no statistically significant difference( $p$-value was 0.282 and 0.681 , Fig. 6b-c).

We also used the cBioPortal dataset to calculate the Pearson's correlation coefficient of S100s with each other and assess whether these genes were correlated with each other(Fig. 7a). The results shown that there was a high correlation between these genes. In addition, we performed a PPI network and explored the potential interaction among S100s by using STRING database(Fig. 7b). As shown in, the PPI network consists of 20 nodes and 74 edges. The results revealed that $S 100$ s were directly and indirectly connected to one another and S100A16 was only associated with S100A14, and other S100s displayed 
close mutual protein-protein interaction. In addition, we constructed a gene-gene interaction network of S100s and their neighbours genes by using GeneMANIA. The results revealed that 20 genes such as TCHHL1, HRNR, FLG2, RPTN, S100A7L2, FLG, TCHH, CRNN, SNTN, CABP7, CALN1, CABP2, KCNIP4, PVALB, MICU3, MYL5, OCM, EFCAB3, CAPSL and GUCA1A, were mainly correlated with the regulation and function of S100s in PAAD(Fig. 7c).

\section{Functional Enrichment Analysis of S100s in PAAD patients}

We used the Metascape to explore the functions of S100s by analyzing GO and KEGG. GO enrichment analysis included biological processes (BP), cellular components (CC) and molecular functions (MF). The analysis shown that the 8 most enriched terms, including calcium ion binding, calcium-dependent protein binding, RAGE receptor binding, S100 protein binding, cornified envelope, leukocyte degranulation, perinuclear region of cytoplasm and response to metal ion (Fig. 8a and Table 2). In addition, we constructed a enriched terms network, colored by $p$-value. Additionally, to further understand the relationship between S100s and PAAD, we constructed PPI Enrichment Analysis. We found that the biological processes were primarily linked to calcium-dependent protein binding, calcium ion binding, protein homodimerization activity, cornified envelope, cornification and keratinization(Fig. 8c-e).

Table 2

The enrichment analysis of S100s in PAAD patients(GeneMANIA)

\begin{tabular}{|c|c|c|c|c|c|c|}
\hline GO & Category & Description & Count & $\%$ & $\log 10(P)$ & $\log 10(q)$ \\
\hline GO:0005509 & $\begin{array}{l}\text { GO Molecular } \\
\text { Functions }\end{array}$ & calcium ion binding & 39 & 97.50 & -61.12 & -56.76 \\
\hline GO:0048306 & $\begin{array}{l}\text { GO Molecular } \\
\text { Functions }\end{array}$ & $\begin{array}{l}\text { calcium-dependent } \\
\text { protein binding }\end{array}$ & 23 & 57.50 & -48.59 & -44.53 \\
\hline G0:0050786 & $\begin{array}{l}\text { GO Molecular } \\
\text { Functions }\end{array}$ & $\begin{array}{l}\text { RAGE receptor } \\
\text { binding }\end{array}$ & 7 & 17.50 & -18.10 & -14.21 \\
\hline GO:0044548 & $\begin{array}{l}\text { GO Molecular } \\
\text { Functions }\end{array}$ & S100 protein binding & 4 & 10.00 & -8.46 & -4.70 \\
\hline GO:0001533 & $\begin{array}{l}\text { GO Cellular } \\
\text { Components }\end{array}$ & cornified envelope & 5 & 12.50 & -8.28 & -4.62 \\
\hline GO:0043299 & $\begin{array}{l}\text { GO Biological } \\
\text { Processes }\end{array}$ & $\begin{array}{l}\text { leukocyte } \\
\text { degranulation }\end{array}$ & 9 & 22.50 & -7.30 & -3.84 \\
\hline G0:0048471 & $\begin{array}{l}\text { GO Cellular } \\
\text { Components }\end{array}$ & $\begin{array}{l}\text { perinuclear region of } \\
\text { cytoplasm }\end{array}$ & 9 & 22.50 & -6.22 & -3.20 \\
\hline GO:0010038 & $\begin{array}{l}\text { GO Biological } \\
\text { Processes }\end{array}$ & response to metal ion & 4 & 10.00 & -2.81 & -0.27 \\
\hline
\end{tabular}


S100s may affect the outcomes of PAAD patients by taking part in immune cells infiltration. Hence, we used TIMER 2.0 Databases to investigate the association between the S100s and Tumor-Infiltrating Immune Cells(Fig. 9). The results showed that there was a positive association between S100A1 and $\mathrm{CD} 4^{+} \mathrm{T}$ cells infiltration, however, there was a negative association between S100A1 and CD ${ }^{+} \mathrm{T}$ cells, $M \varphi$ and DCs infiltration. S100A3 and S100A4 were positively related with Neutrophils and DCs infiltration, and S100A3 was also positively associated with $\mathrm{CD} 4^{+} \mathrm{T}$ cells infiltration. S100A5 and S100A6 were negatively related with $C D 8^{+} T$ cells and $M \varphi$ infiltration, and S100A6 was also negatively associated with Neutrophils and DCs infiltration. S100A7/A10/A11 were negatively correlated with $M \varphi$ infiltration. S100A8/A9/A12/B/Z were positively related with $C D 8^{+} T$ cells, $C D 4^{+} T$ cells, $M \varphi$, Neutrophils and DCs infiltration, and S100A12/B/Z were also positively associated with $B$ cells infiltration. There was a positive relationship between $\mathrm{S} 100 \mathrm{~A} 13$ and $\mathrm{CD} 4^{+} \mathrm{T}$ cells infiltration, while there was a negative relationship between S100A13 and $M \varphi$ infiltration. S100A14 and S100A16 were negatively related with $\mathrm{CD} 4^{+} \mathrm{T}$ cells, $\mathrm{M} \varphi$ and $\mathrm{DC}$ infiltration, and there was a negative relationship between $\mathrm{S} 100 \mathrm{A6}$ and $\mathrm{CD} 8^{+} \mathrm{T}$ cells infiltration. There was a negative association between S100P and CD4 ${ }^{+} \mathrm{T}$ cells, M $\varphi$ infiltration. However, S100A7A/S100G were not correlated with immune cells infiltration. Additionally, We used Cox proportional risk model to explore the association between S100s and Tumor-Infiltrating Immune Cells. The results revealed that $\mathrm{B}$ cells $(p=0.024), \mathrm{DCs}(p=0.025), \operatorname{S100A} 1(p=0.001), \operatorname{S100A5}(p=0.026)$, $\mathrm{S} 100 \mathrm{~A} 6(p=0.025), \mathrm{S} 100 \mathrm{~A} 8(p=0.004), \mathrm{S} 100 \mathrm{~A} 9(p=0.017), \mathrm{S} 100 \mathrm{~A} 13(p=0.039), \mathrm{S} 100 \mathrm{~A} 14(p=0.006)$ were obviously related with prognosis of patients with $\operatorname{PAAD}($ Table 3$)$. 
Table 3

Cox proportional hazard model of S100s and Tumor-Infiltrating Immune Cells in patients with PAAD(TIMER 2.0).

\begin{tabular}{|lllllll|}
\hline & coef & HR & $95 \%$ CI_I & $95 \%$ Cl_u & $p$-value & sig \\
\hline B_cell & 7.559 & 1917.085 & 2.691 & 1365803.767 & 0.024 & $*$ \\
\hline CD8_Tcell & 3.517 & 33.678 & 0.010 & 110982.584 & 0.395 & \\
\hline CD4_Tcell & -7.790 & 0.000 & 0.000 & 1.231 & 0.056 & \\
\hline Macrophage & -0.211 & 0.810 & 0.001 & 509.868 & 0.949 & \\
\hline Neutrophil & -0.524 & 0.592 & 0.000 & 18554686.963 & 0.953 & \\
\hline Dendritic & -5.542 & 0.004 & 0.000 & 0.499 & 0.025 & $*$ \\
\hline S100A1 & -0.454 & 0.635 & 0.489 & 0.824 & 0.001 & $* *$ \\
\hline S100A2 & 0.066 & 1.068 & 0.941 & 1.212 & 0.307 & \\
\hline S100A3 & 0.068 & 1.070 & 0.737 & 1.554 & 0.722 & \\
\hline S100A4 & 0.081 & 1.084 & 0.889 & 1.323 & 0.425 & \\
\hline S100A5 & -0.556 & 0.574 & 0.351 & 0.937 & 0.026 & $*$ \\
\hline S100A6 & -0.713 & 0.490 & 0.263 & 0.914 & 0.025 & $*$ \\
\hline S100A7 & -0.253 & 0.776 & 0.529 & 1.139 & 0.195 & \\
\hline S100A7A & 0.795 & 2.215 & 0.078 & 63.108 & 0.642 & \\
\hline S100A8 & 0.644 & 1.905 & 1.224 & 2.964 & 0.004 & $* *$ \\
\hline S100A9 & -0.413 & 0.662 & 0.471 & 0.929 & 0.017 & $*$ \\
\hline S100A10 & -0.038 & 0.963 & 0.48 & 1.932 & 0.915 & \\
\hline S100A11 & 0.698 & 2.010 & 0.938 & 4.306 & 0.073 & \\
\hline S100A12 & -0.092 & 0.912 & 0.575 & 1.446 & 0.696 & \\
\hline S100A13 & 0.683 & 1.979 & 1.035 & 3.783 & 0.039 & $*$ \\
\hline S100A14 & 0.394 & 1.483 & 1.122 & 1.961 & 0.006 & $* *$ \\
\hline S100A16 & -0.435 & 0.647 & 0.314 & 1.333 & 0.238 & \\
\hline S100B & -0.126 & 0.881 & 0.639 & 1.215 & 0.441 & \\
\hline S100G & 0.252 & 1.286 & 0.845 & 1.958 & 0.241 & \\
\hline S100P & -0.007 & 0.993 & 0.819 & 1.204 & 0.943 & \\
\hline
\end{tabular}

* indicates $p<0.05$, ** indicates $p<0.01$. 


\begin{tabular}{|c|c|c|c|c|c|}
\hline & coef & HR & 95\%Cl_I & 95\%Cl_u & $p$-value sig \\
\hline S100Z & -0.667 & 0.513 & 0.221 & 1.195 & 0.122 \\
\hline
\end{tabular}

\section{Discussion}

Accumulative researches indicated that $\mathrm{S} 100$ s dysfunction plays very important role in many cancers ${ }^{4}$. The functions of S100s in certain cancers has been reported, but comprehensive analysis of the whole twenty S100s in PAAD patients has not been clarified. In our study, we found that the S100A2/A3/A4/A6/A8/A9/A10/A11/A13/A14/A16/B/P mRNA expression were significantly upregulated in PAAD patients. Survival analysis found that the increased levels of S100A2/A3/A5/A10/A11/A14/A16 were significantly correlated with poor OS, whereas the increased levels of $S 100 A 1 / B / G / Z$ were strongly correlated with good OS. Our study suggested that S100A2/A3/A10/A11/A14 /A16 could be used as novel prognostic or therapeutic biomarkers.

S100A2 was overexpressed and correlated with poor prognosis and progression in PAAD ${ }^{13}$. Biankin et al. revealed that $\mathrm{S100A2}$ expression is a good predictor of response to pancreatectomy for PAAD ${ }^{27}$. Bachet et al. showed that the higher expression of S100A2 predicts good DFS and OS in patients receiving adjuvant therapy and should be evaluated as a predictive biomarker in PAAD ${ }^{28}$. Wen et al. revealed that the S100A2 is downregulated in radioresistant pancreatic cells, suggesting that S100A2 may be involved in radioresistance of PAAD cells ${ }^{29}$. In our research, we found that the S100A2 was significantly overexpressed in PAAD tissues, and there was a relationship between S100A2 and short OS and DFS in PAAD patients. However, there was no association between S100A2 and the tumor stage in PAAD patients.

S100A3 plays a vital role in some cancers, for instance, ovarian cancer, gastric cancer and colorectal Cancer ${ }^{8,30,31}$. But the role of S100A3 in PAAD patients has not been investigated. In our research, we first revealed that the S100A3 expression was significantly higher in PAAD patients. Moreover, high S100A3 expression was linked with advanced tumor stage and worse OS in PAAD patients, however, the expression of S100A3 has nothing to do with DFS in PAAD patients. The role and mechanism of S100A3 in PAAD still need to be confirmed by a large number of studies in the future.

S100A10, a plasminogen receptor, was overexpressed in PAAD patients, as a new putative biomarker and could promote the growth and invasion of pancreatic tumor. The expression of S100A10 was driven by methylation of the $\sim 400$ bp promoter region and oncogenic KRAS ${ }^{612 D}$. S100A10 promoted the growth of pancreatic tumors and regulated the expression of VEGF and CCND $1^{32}$. However, the underlying mechanisms are needed to explore further. In our research, the analysis indicated that the S100A10 expression was aberrantly up-regulated in PAAD patients. Moreover, high S100A10 expression was 
related with advanced tumor stage. The results indicated that the expression of S100A10 may result in short OS and DFS in PAAD patients.

S100A11 was over-expressed in the early stage of carcinogenesis and down-regulated during the progression of pancreatic cancer ${ }^{33}$. Xiao et al. shown that the S100A11 was related with bad prognosis and S100A11 was an independent prognostic indicator of PAAD, and further research confirmed that S100A11 promoted the viability and proliferation of human PAAD PANC-1 cells through the upregulation of the PI3K/AKT pathway ${ }^{16,34}$. Mitsui et al. found that the secretory S100A11 induced upregulation mobility of PAAD cells by activating the surrounding fibroblasts through the S100A11-RAGE-TPL2-COX2 pathway ${ }^{35}$. Takamatsu et al. identified that extracellular S100A11 promoted the proliferation of fibroblasts through the RAGE-MyD88-mTOR-p70 S6 kinase pathway ${ }^{36}$. In this research, the data suggested that the S100A11 expression was aberrantly up-regulated in PAAD patients. Nevertheless, high S100A11 expression was related to advanced tumor stage and shorter OS. However, there was no association between S100A11 and tumor stage in PAAD patients.

S100A14 in PAAD has been rarely reported. In a recently published study, Zhu et al. revealed that S100A14 was significantly over-expressed in PAAD and promoted the progression and gemcitabine resistance ${ }^{37}$. Our results revealed that the S100A14 expression was significantly over-expressed in PAAD patients. Moreover, the S100A14 expression was related with advanced tumor stage and bad clinical outcomes. However, the S100A14 expression in PAAD patients has no effect on DFS of PAAD patients.

S100A16 is an important member of S100s. In a recent report, Tu et al. used bioinformatics to investigate the S100A16 expression and its prognostic in PAAD patients, and confirmed that S100A16 expression was up-regulated in PAAD patients and affected the prognosis of PAAD patients ${ }^{38}$. Meanwhile, Experiments by Fang et al. confirmed that S100A16 was overexpressed in PAAD and promoted the metastasis and progression of PAAD through FGF19-mediated Akt and ERK1/2 signaling pathways ${ }^{39}$. Li et al. reported that S100A16 promoted the metastasis by inducing EMT through up-regulating TWIST1 expression and activating the STAT3 signalling pathway in PAAD ${ }^{40}$. Our results revealed S100A16 expression was significantly over-expressed in PAAD. Moreover, the expression of S100A16 was associated with advanced tumor stage. The above results suggested that the higher S100A10 expression led to short OS and DFS in PAAD patients.

Previous study has focused on tumor Immune Infiltration and its role in PAAD. Ino et al. reported that more $\mathrm{CD} 4^{+}$and $\mathrm{CD} 8^{+} \mathrm{T}$ cells infiltration are a prerequisite for longer survival in PAAD patients, and the $\mathrm{CD} 4^{+} \mathrm{CD} 8^{+} \mathrm{T}$ cells status is an independent prognostic factor ${ }^{41}$. Jiang et al. revealed that DCs were observed to abundantly infiltrate the tumor tissue, but the function of DCs always were impaired ${ }^{42}$. Di et al. found that the density of Tumor-associated macrophages were correlated with worse outcomes and distant metastasis in PAAD patients ${ }^{43}$. In our study, the results revealed the S100A3 was positively related with the $\mathrm{CD} 4^{+} \mathrm{T}$ cells, Neutrophils and DCs infiltration. The transcription levels of S100A10/A11 were negatively correlated with $M \varphi$ infiltration. There was a negative relationship between the S100A14 and 
$\mathrm{CD} 4^{+} \mathrm{T}$ cells, $\mathrm{M} \varphi$ and DCs infiltration. There was a negative association between the S100A16 and CD $8^{+}$ $T$ cells, $C D 4^{+} T$ cells, $M \varphi$ and DCs infiltration. The results indicated that $S 100$ s may reflect the anti-tumor immunity in PAAD. The Cox proportional risk model revealed that the S100A1/A5/A6/A8/A9/A13/A14 expression was obviously related with the outcomes of PAAD patients.

Nevertheless, our study has some limitations. Because of complex post-transcriptional modifications in cells, the transcriptional levels did not completely reflect the protein levels in PAAD. To further clarify the expression and detailed mechanism of S100s in PAAD, numerous basic experiments are still needed in the future.

\section{Conclusion}

In conclusion, we systematically analyzed the $\$ 100$ s expression and its association with outcomes and tumor immune microenvironment in PAAD patients. Our results indicated that the S100A2/A3/A4/A6/A8/A9/A10/A11/A13/A14/A16/B/P mRNA expression were significantly upregulated in PAAD patients. Survival analysis found that the increased levels of S100A2/A3/A5/A10/A11/A14/A16 were significantly correlated with poor OS, whereas the increased levels of S100A1/B/G/Z were strongly correlated with good OS. We found significant correlations among S100s and Tumor-Infiltrating Immune Cells. Additionally, The Cox proportional risk model revealed that $B$ cells, Dendritic cells and S100A1/A5/A6/A8/A9/A13/A14 were obviously related with prognosis of patients with PAAD. Our results reveal that S100s may be a new target for the diagnosis and treatment of PAAD and provide evidence for the clinical application of S100s inhibitors in PAAD patients.

\section{Abbreviations}

S100s

S100 family members

PAAD

Pancreatic Adenocarcinoma

GEPIA

Gene Expression Profiling Interactive Analysis

TCGA

The Cancer Genome Atlas

GTEx

Genotype-tissue Expression

OS

Overall survival

DFS

Disease-free survival

PPI

protein-protein interaction 
GO

gene ontology

KEGG

Kyoto Encyclopedia of Genes and Genomes

$\mathrm{BP}$

biological processes

CC

cellular components

MF

molecular functions

Dendritic cells

DCs

Macrophages

$\mathrm{M \varphi}$.

\section{Declarations}

\section{Acknowledgements}

None

\section{Authors' contributions}

$\mathrm{MZ}$ and FX contributed to develop the idea and design of this study. YR and BC contributed to analyze the data and write the manuscript. All authors read and approved the manuscript for publication.

\section{Funding}

This study was supported by the Medicine Science and Technology Research Project of Henan Province(LHGJ20190256 and LHGJ20190017).

\section{Availability of data and materials}

The data used to support the findings of this study are included within the article. All methods were carried out in accordance with relevant guidelines and regulations as publicly available data is used.

\section{Ethics approval and consent to participate}

All patients from the TCGA database gave written informed consent to participate in any scientific researches. 


\section{Consent for publication}

Not applicable.

\section{Competing interests}

The authors declare that there is no conflict of interest regarding the publication of this paper.

\section{References}

1 Mizrahi, J. D., Surana, R., Valle, J. W. \& Shroff, R. T. Pancreatic cancer. Lancet395, 2008-2020, doi:10.1016/S0140-6736(20)30974-0 (2020).

2 Siegel, R. L., Miller, K. D. \& Jemal, A. Cancer statistics, 2020. CA: a cancer journal for clinicians70, 7-30, doi:10.3322/caac.21590 (2020).

3 Rahib, L. et al. Projecting cancer incidence and deaths to 2030: the unexpected burden of thyroid, liver, and pancreas cancers in the United States. Cancer research74, 2913-2921, doi:10.1158/0008-5472.CAN14-0155 (2014).

4 Allgower, C. et al. Friend or Foe: S100 Proteins in Cancer. Cancers12, doi:10.3390/cancers12082037 (2020).

5 Liu, Y. et al. Prognostic Roles of mRNA Expression of S100 in Non-Small-Cell Lung Cancer. BioMed research internationa/2018, 9815806, doi:10.1155/2018/9815806 (2018).

6 Yang, X. Y. et al. Expression and clinical significance profile analysis of S100 family members in human acute myeloid leukemia. European review for medical and pharmacological sciences24, 7324-7334, doi:10.26355/eurrev_202007_21896 (2020).

7 Xiong, T. F., Pan, F. Q. \& Li, D. Expression and clinical significance of S100 family genes in patients with melanoma. Melanoma research29, 23-29, doi:10.1097/CMR.0000000000000512 (2019).

8 Bai, Y., Li, L. D., Li, J. \& Lu, X. Prognostic values of S100 family members in ovarian cancer patients. BMC cancer 18,1256 , doi:10.1186/s12885-018-5170-3 (2018).

9 Ma, N., Zhu, L., Yang, L., Cui, Y. \& Zhan, Y. Prognostic values of S100 family mRNA expression in ovarian cancer. Cancer biomarkers : section A of Disease markers25, 67-78, doi:10.3233/CBM-182276 (2019).

10 Zhang, S. et al. Distinct prognostic values of S100 mRNA expression in breast cancer. Scientific reports7, 39786, doi:10.1038/srep39786 (2017). 
11 Huang, S. et al. Impact of S100A4 Expression on Clinicopathological Characteristics and Prognosis in Pancreatic Cancer: A Meta-Analysis. Disease markers2016, 8137378, doi:10.1155/2016/8137378 (2016).

12 Tsukamoto, N. et al. The expression of S100A4 in human pancreatic cancer is associated with invasion. Pancreas42, 1027-1033, doi:10.1097/MPA.0b013e31828804e7 (2013).

13 Ohuchida, K. et al. Over-expression of S100A2 in pancreatic cancer correlates with progression and poor prognosis. The Journal of pathology213, 275-282, doi:10.1002/path.2250 (2007).

14 Biankin, A. V. et al. Expression of S100A2 calcium-binding protein predicts response to pancreatectomy for pancreatic cancer. Gastroenterology137, 558-568, 568 e551-511, doi:10.1053/j.gastro.2009.04.009 (2009).

15 Vimalachandran, D. et al. High nuclear S100A6 (Calcyclin) is significantly associated with poor survival in pancreatic cancer patients. Cancer research65, 3218-3225, doi:10.1158/0008-5472.CAN-044311 (2005).

16 Xiao, M. B. et al. High expression of S100A11 in pancreatic adenocarcinoma is an unfavorable prognostic marker. Medical oncology29, 1886-1891, doi:10.1007/s12032-011-0058-y (2012).

17 Sealfon, S. C. \& Chu, T. T. RNA and DNA microarrays. Methods in molecular biology671, 3-34, doi:10.1007/978-1-59745-551-0_1 (2011).

18 Rhodes, D. R. et al. Oncomine 3.0: genes, pathways, and networks in a collection of 18,000 cancer gene expression profiles. Neoplasia9, 166-180, doi:10.1593/neo.07112 (2007).

19 Tang, Z., Kang, B., Li, C., Chen, T. \& Zhang, Z. GEPIA2: an enhanced web server for large-scale expression profiling and interactive analysis. Nucleic acids research47, W556-W560, doi:10.1093/nar/gkz430 (2019).

20 Cancer Genome Atlas, N. Comprehensive molecular portraits of human breast tumours. Nature490, 6170, doi:10.1038/nature11412 (2012).

$21 \mathrm{Gao}, \mathrm{J}$. et al. Integrative analysis of complex cancer genomics and clinical profiles using the cBioPortal. Science signaling6, pl1, doi:10.1126/scisignal.2004088 (2013).

22 Cerami, E. et al. The cBio cancer genomics portal: an open platform for exploring multidimensional cancer genomics data. Cancer discovery2, 401-404, doi:10.1158/2159-8290.CD-12-0095 (2012).

23 Zhou, Y. et al. Metascape provides a biologist-oriented resource for the analysis of systems-level datasets. Nature communications10, 1523, doi:10.1038/s41467-019-09234-6 (2019).

24 Szklarczyk, D. et al. STRING v11: protein-protein association networks with increased coverage, supporting functional discovery in genome-wide experimental datasets. Nucleic acids research47, D607- 
D613, doi:10.1093/nar/gky1131 (2019).

$25 \mathrm{Li}$, T. et al. TIMER: A Web Server for Comprehensive Analysis of Tumor-Infiltrating Immune Cells. Cancer research77, e108-e110, doi:10.1158/0008-5472.CAN-17-0307 (2017).

$26 \mathrm{Li}$, B. et al. Comprehensive analyses of tumor immunity: implications for cancer immunotherapy. Genome biology17, 174, doi:10.1186/s13059-016-1028-7 (2016).

27 Andrew V, B. Expression of S100A2 calcium-binding protein predicts response to pancreatectomy for pancreatic cancer. Gastroenterology2 (2009).

28 Bachet, J. B. et al. S100A2 is a predictive biomarker of adjuvant therapy benefit in pancreatic adenocarcinoma. European journal of cancer49, 2643-2653, doi:10.1016/j.ejca.2013.04.017 (2013).

29 Wen, Q., Zhao, Y. P., Chen, G., Zhang, F. Q. \& Zhang, T. P. [Expression of S100A2 in secondarily radioresistant pancreatic cancer cells and significance thereof]. Zhonghua yi xue za zhi86, 2817-2820 (2006).

30 Wang, C. et al. Distinct prognostic roles of S100 mRNA expression in gastric cancer. Pathology, research and practice215, 127-136, doi:10.1016/j.prp.2018.10.034 (2019).

31 Zeng, M. L. et al. An Integrated Bioinformatic Analysis of the S100 Gene Family for the Prognosis of Colorectal Cancer. BioMed research internationa/2020, 4746929, doi:10.1155/2020/4746929 (2020).

32 Bydoun, M. et al. S100A10, a novel biomarker in pancreatic ductal adenocarcinoma. Molecular oncology12, 1895-1916, doi:10.1002/1878-0261.12356 (2018).

33 Ohuchida, K. et al. S100A11, a putative tumor suppressor gene, is overexpressed in pancreatic carcinogenesis. Clinical cancer research : an official journal of the American Association for Cancer Research12, 5417-5422, doi:10.1158/1078-0432.CCR-06-0222 (2006).

34 Xiao, M. et al. S100A11 promotes human pancreatic cancer PANC-1 cell proliferation and is involved in the PI3K/AKT signaling pathway. Oncology letters15, 175-182, doi:10.3892/ol.2017.7295 (2018).

35 Mitsui, Y. et al. Upregulation of Mobility in Pancreatic Cancer Cells by Secreted S100A11 Through Activation of Surrounding Fibroblasts. Oncology research27, 945-956, doi:10.3727/096504019X15555408784978 (2019).

36 Takamatsu, H. et al. Extracellular S100A11 Plays a Critical Role in Spread of the Fibroblast Population in Pancreatic Cancers. Oncology research27, 713-727, doi:10.3727/096504018X15433161908259 (2019).

$37 \mathrm{Zhu}, \mathrm{H}$. et al. S100A14 promotes progression and gemcitabine resistance in pancreatic cancer. Pancreatology : official journal of the International Association of Pancreatology21, 589-598, 
doi:10.1016/j.pan.2021.01.011 (2021).

38 Tu, G. et al. Expressional and Prognostic Value of S100A16 in Pancreatic Cancer Via Integrated Bioinformatics Analyses. Frontiers in cell and developmental biology 9,645641 , doi:10.3389/fcell.2021.645641 (2021).

39 Fang, D. et al. S100A16 promotes metastasis and progression of pancreatic cancer through FGF19mediated AKT and ERK1/2 pathways. Cell biology and toxicology, doi:10.1007/s10565-020-09574-w (2021).

$40 \mathrm{Li}, \mathrm{T}$. et al. S100A16 induces epithelial-mesenchymal transition in human PDAC cells and is a new therapeutic target for pancreatic cancer treatment that synergizes with gemcitabine. Biochemical pharmacology, 114396, doi:10.1016/j.bcp.2020.114396 (2020).

41 Ino, Y. et al. Immune cell infiltration as an indicator of the immune microenvironment of pancreatic cancer. British journal of cancer108, 914-923, doi:10.1038/bjc.2013.32 (2013).

42 Jang, J. E. et al. Crosstalk between Regulatory T Cells and Tumor-Associated Dendritic Cells Negates Anti-tumor Immunity in Pancreatic Cancer. Cell reports20, 558-571, doi:10.1016/j.celrep.2017.06.062 (2017).

43 Di Caro, G. et al. Dual prognostic significance of tumour-associated macrophages in human pancreatic adenocarcinoma treated or untreated with chemotherapy. Gut65, 1710-1720, doi:10.1136/gutjnl-2015-309193 (2016).

\section{Figures}

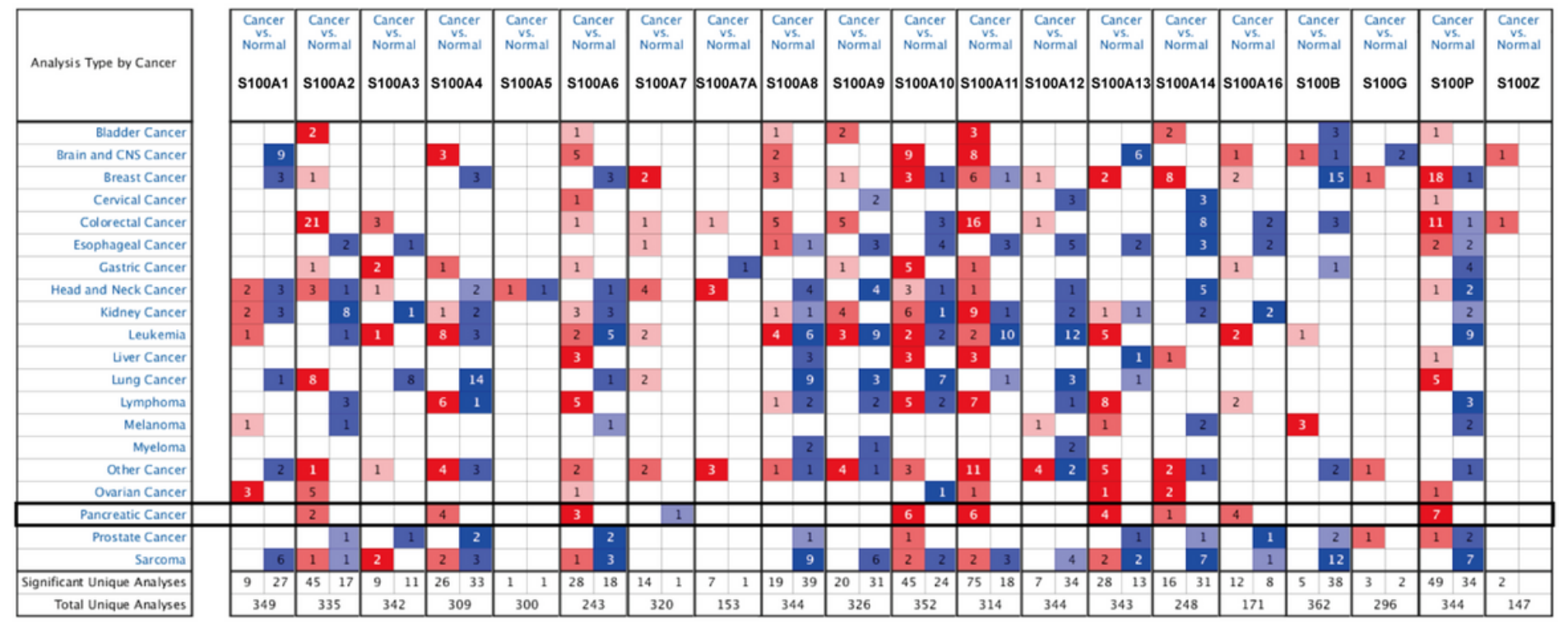

불ำ 
The S100s mRNA expression in various cancers(Oncomine). Numbers represent the number of datasets with the mRNA expression of S100s was up-regulated(red) and down-regulated (blue) significantly. The thresholds were restricted: $p$-value $<0.01$, fold change $\geq 2$, data type: mRNA, gene bank: $10 \%$.
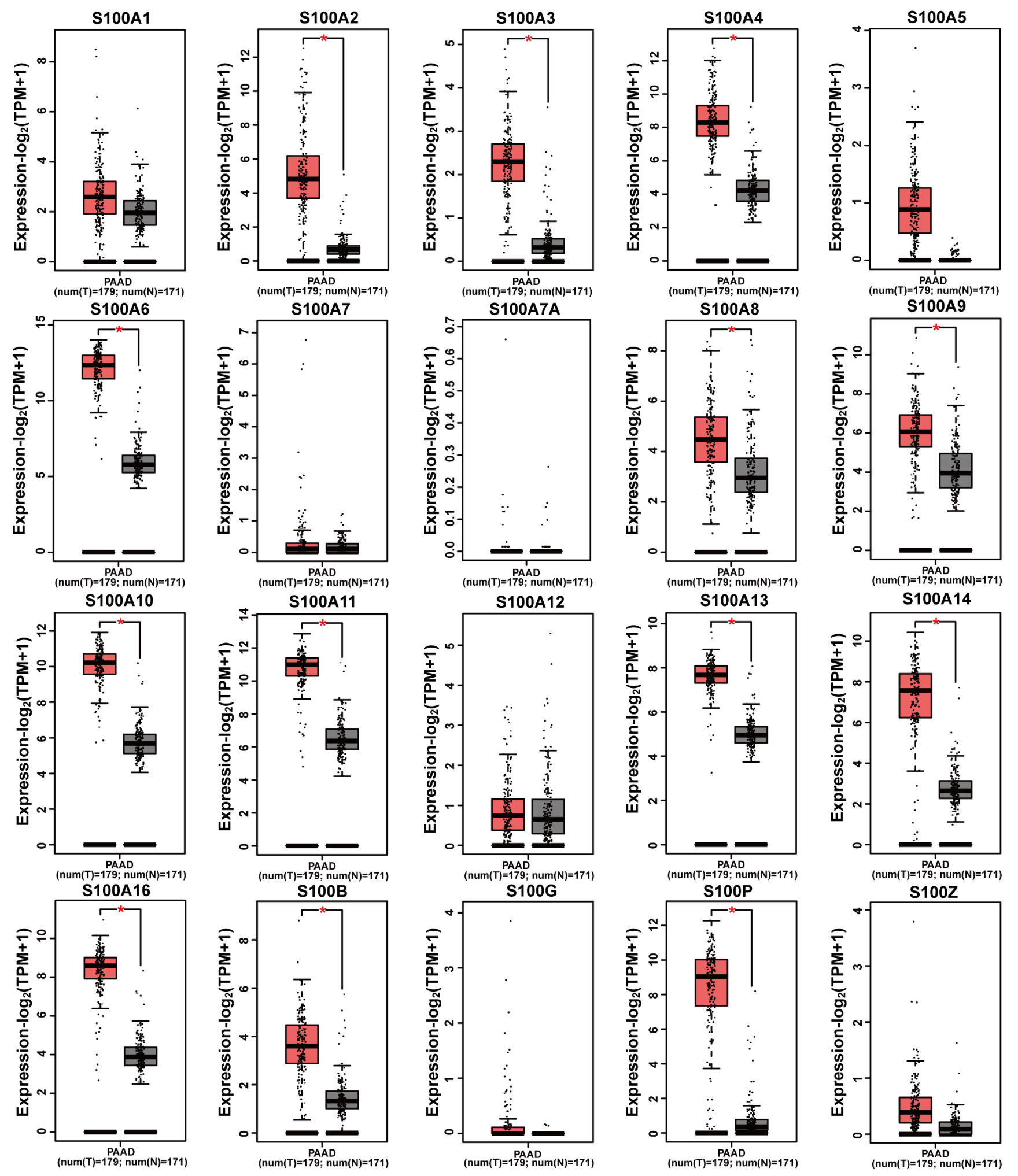

Figure 2 
The mRNA expression of S100s in PAAD patients(GEPIA 2). The $p$-value was set as 0.01 , * indicates a statistically significant difference.
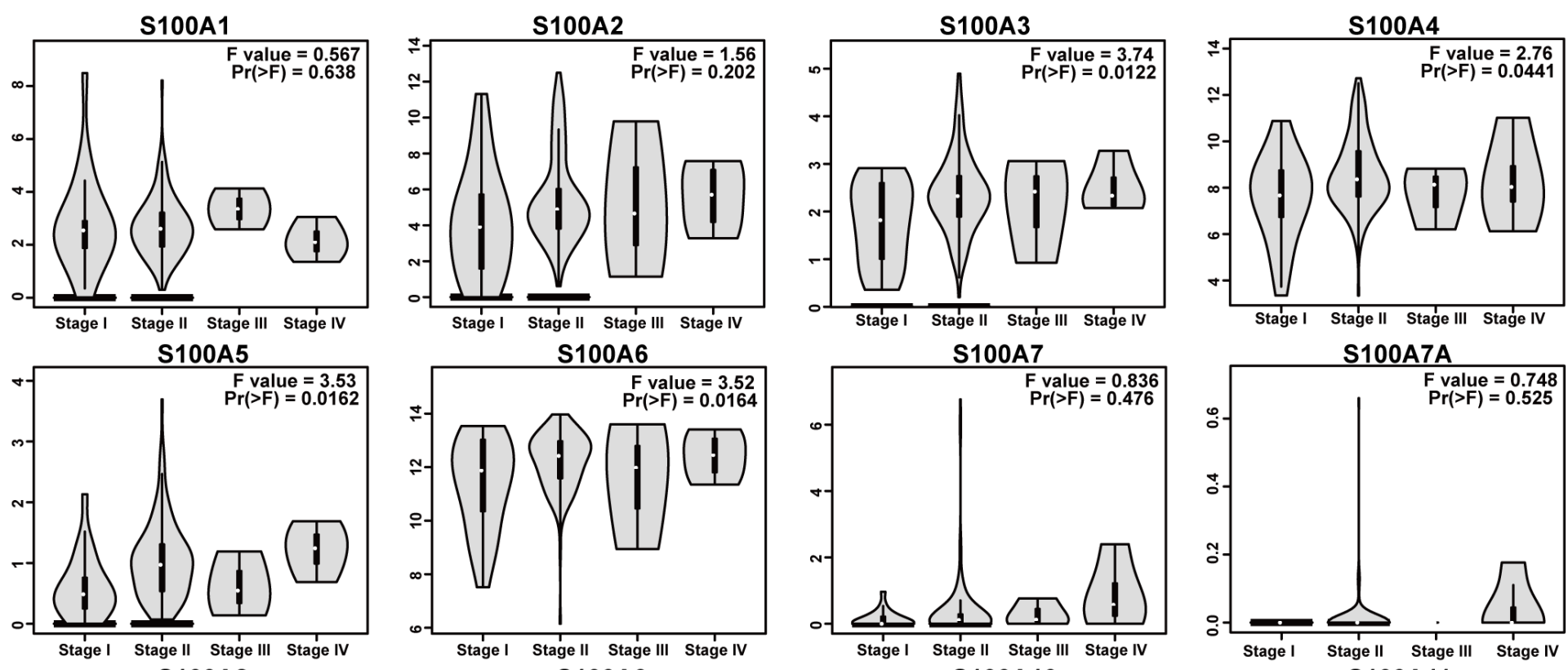

S100A6
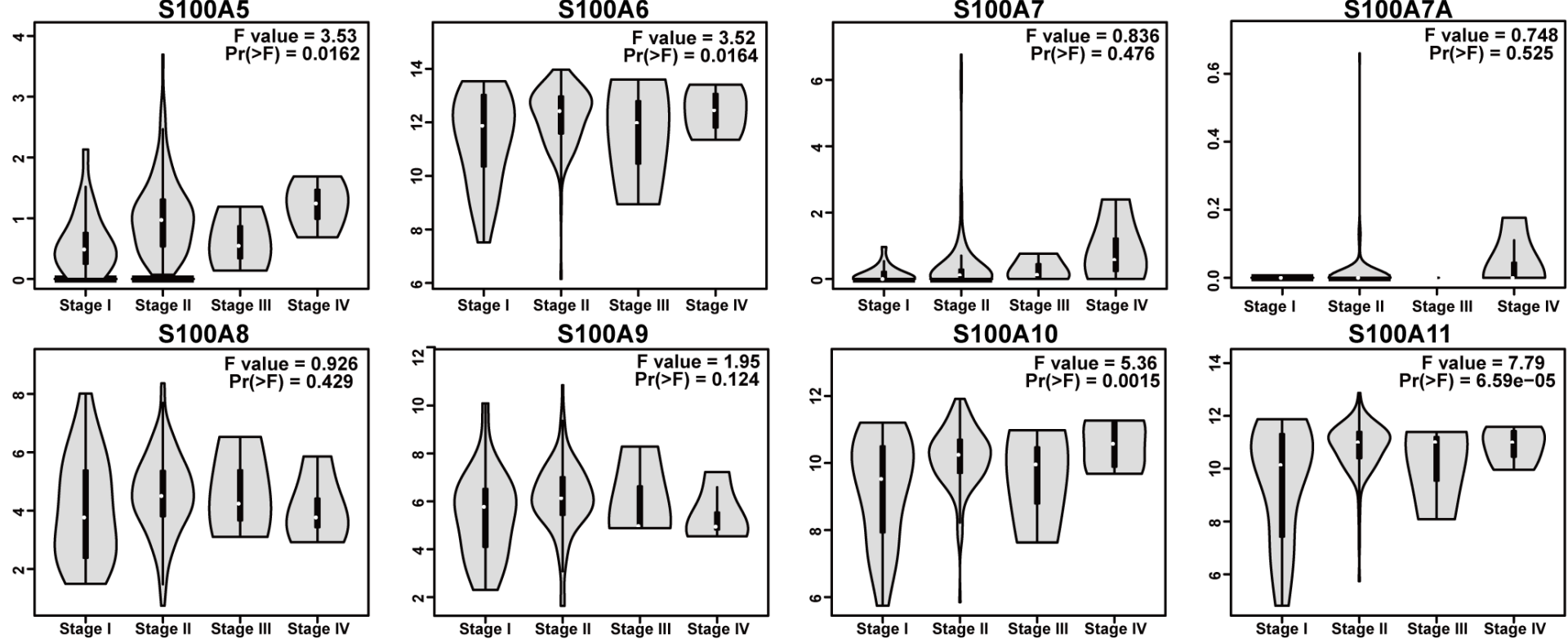

S100A9

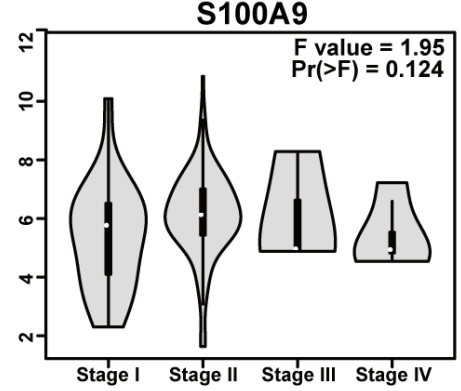

S100A10

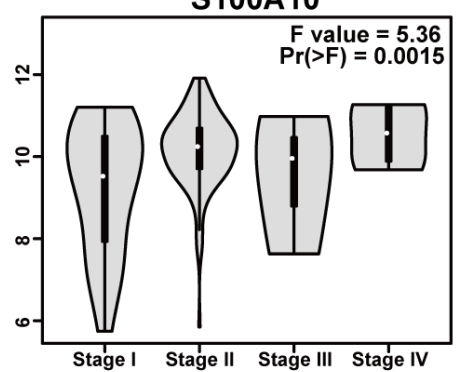

S100A11

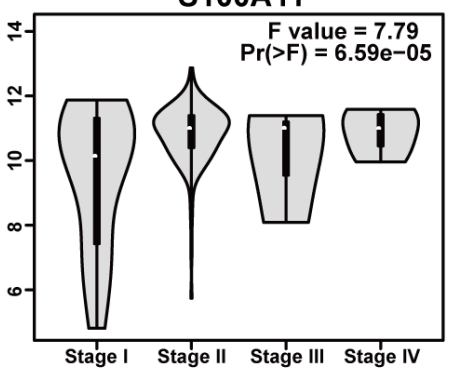

S100A14
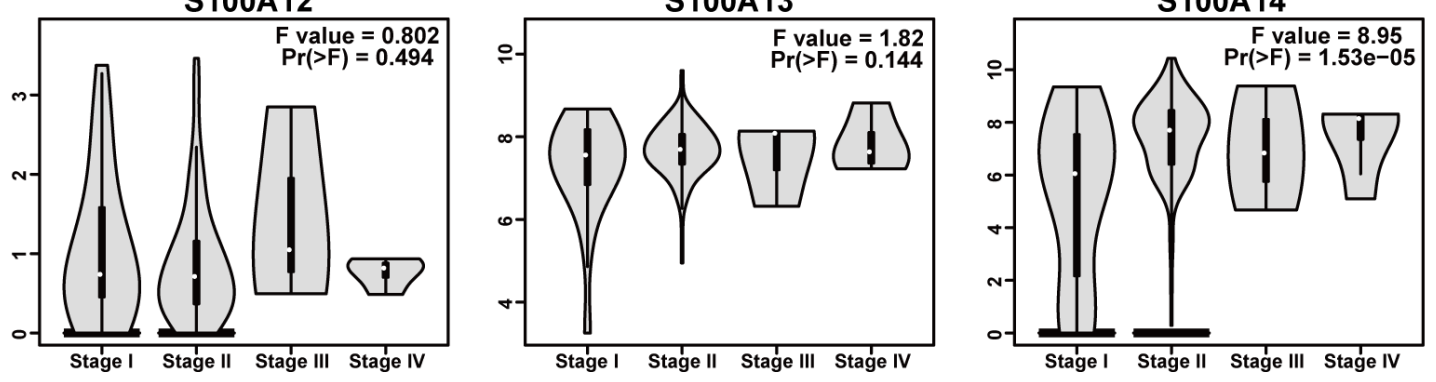

S100A16

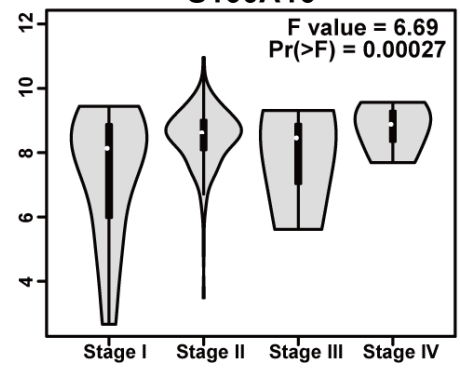

S100G
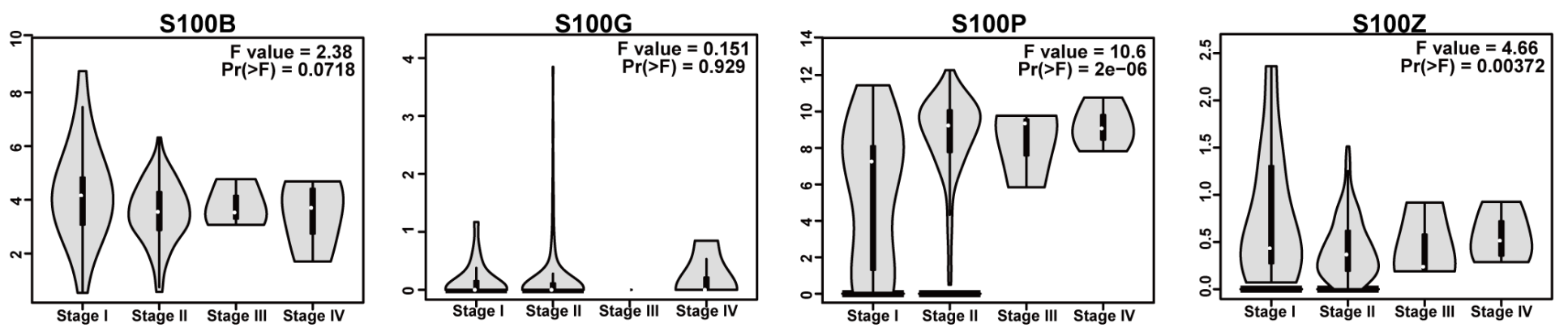

Figure 3

The association between S100s and tumor stage in PAAD patients(GEPIA 2). The $p$-value $<0.05$ was considered to be significant. 

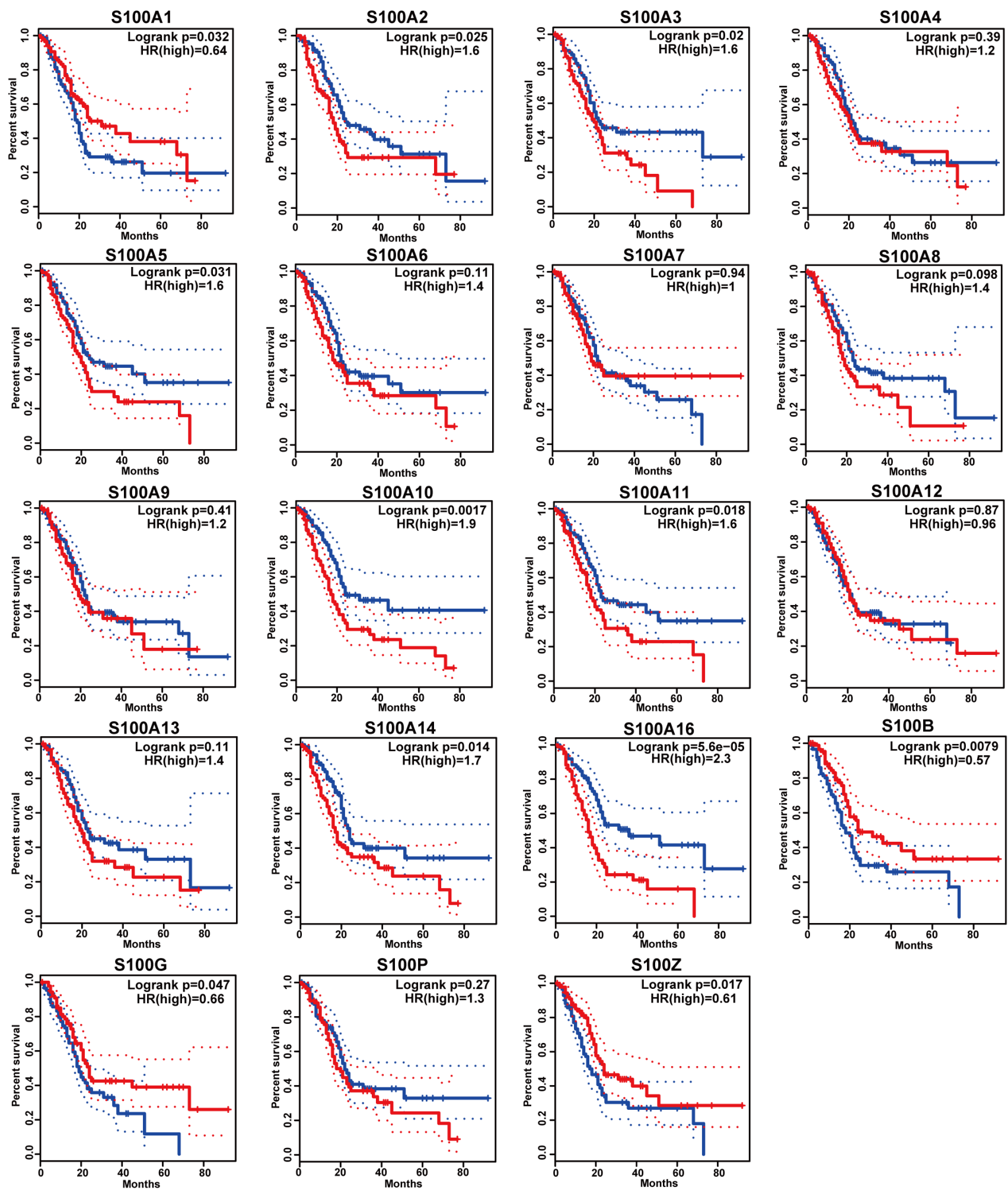

\section{Figure 4}

The prognosis value of S100s in patients with PAAD in the OS curve(GEPIA 2). 

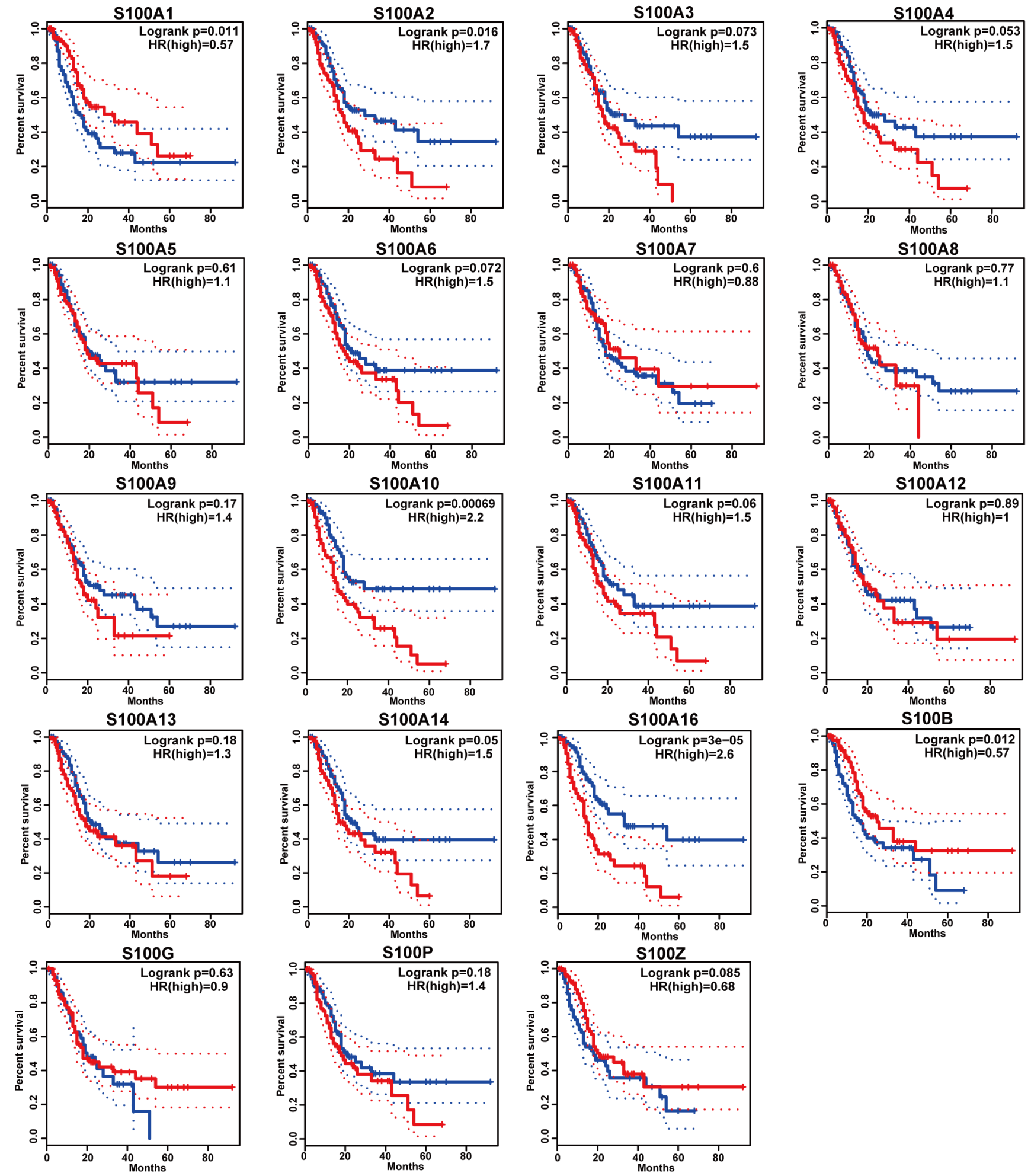

\section{Figure 5}

The prognosis value of S100s in patients with PAAD in the DFS curve(GEPIA 2). 


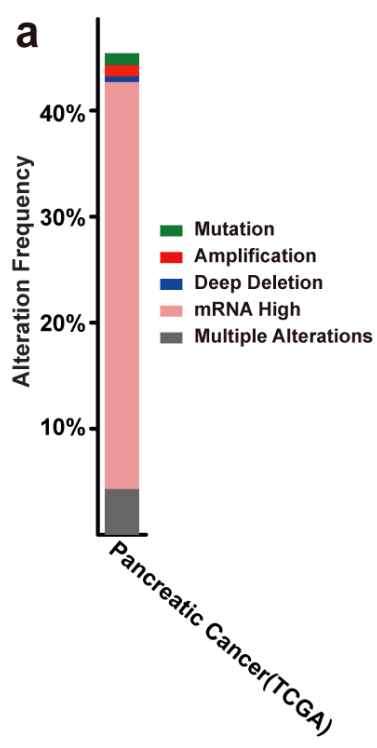

b

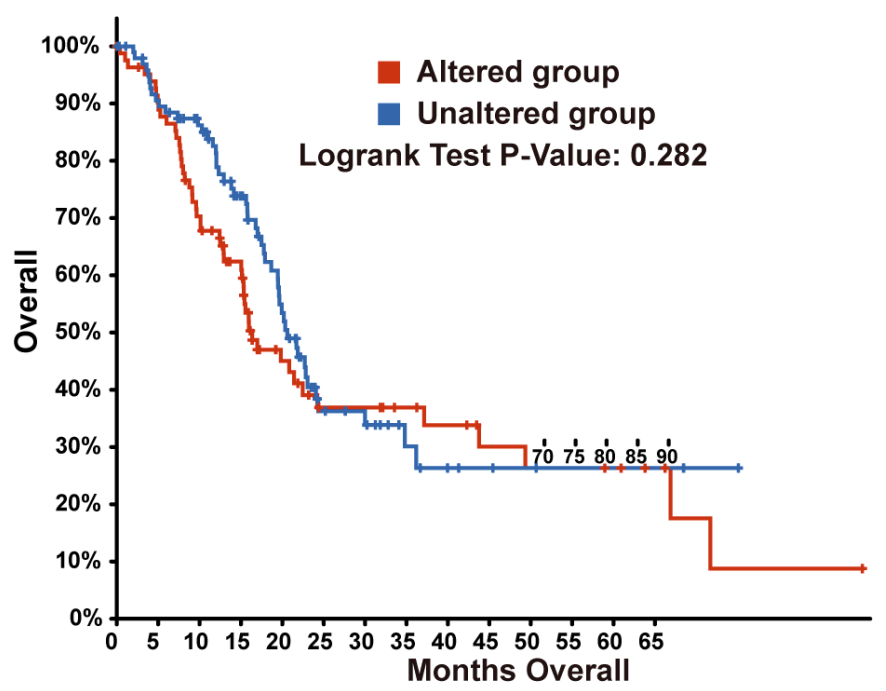

Altered in $84(45 \%)$ of 186 sequenced cases/patients (186)

S100A1 $5 \%$. In || | S100A2 $7 \%$. S100A3 $\quad \mathbf{8} \%$ S100A4 $10 \%$ m S100A5 9\% S100A6 $9 \%$ S100A7 $5 \%$. S100A7A $\quad 4 \%$. S100A8 $5 \%$ \& S100A9 $6 \%$.

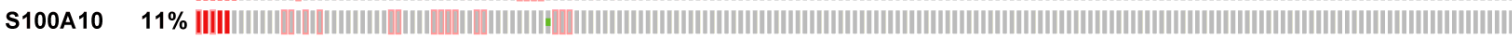
S100A11 $8 \%$. S100A12 $7 \%$ In

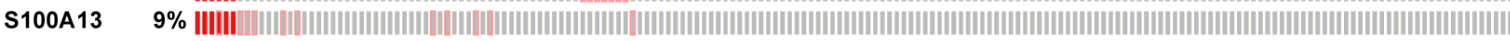

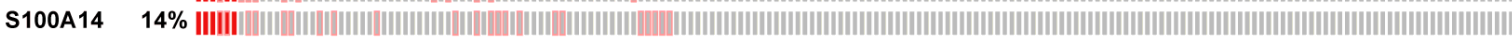
S100A16 19\% In S100B $1.1 \%$ | S100G $2.2 \%$ || S100P $\quad 8 \%$. S100Z $5 \%$. Genetic Alteration | Missense Mutation (unknown significance) | Amplification | Deep Deletion $\mid$ mRNA High No alterations

C

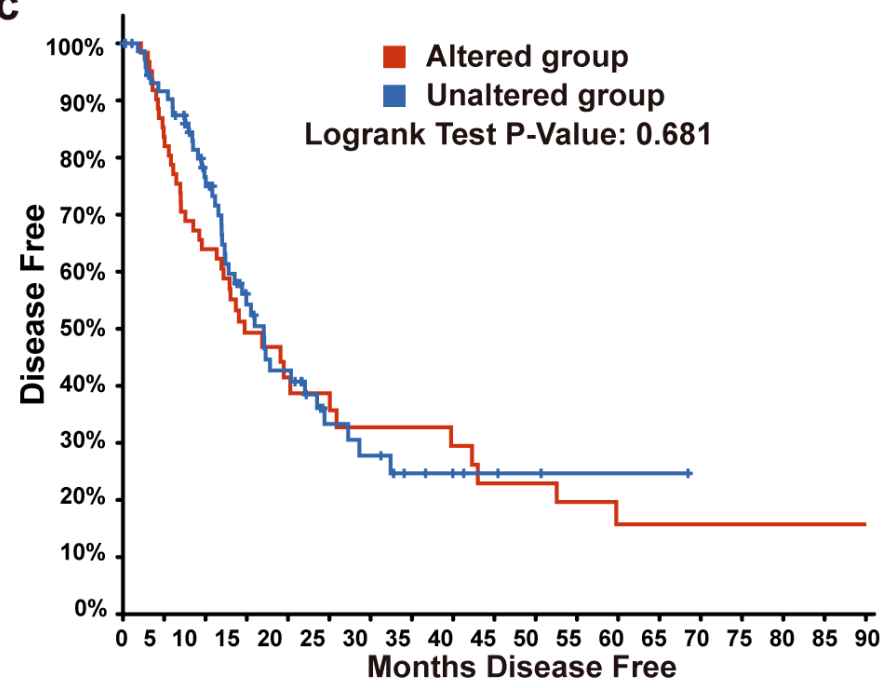

\section{Figure 6}

Alteration frequency of S100s and survival analysis in PAAD patients(cBioPortal). (a) Summary of S100s alterations in PAAD patients. OS(b) and DFS(c) in PAAD patients with and without S100s alterations by Kaplan-Meier plots. 
a

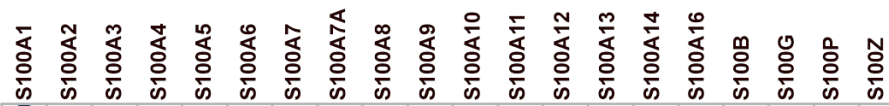

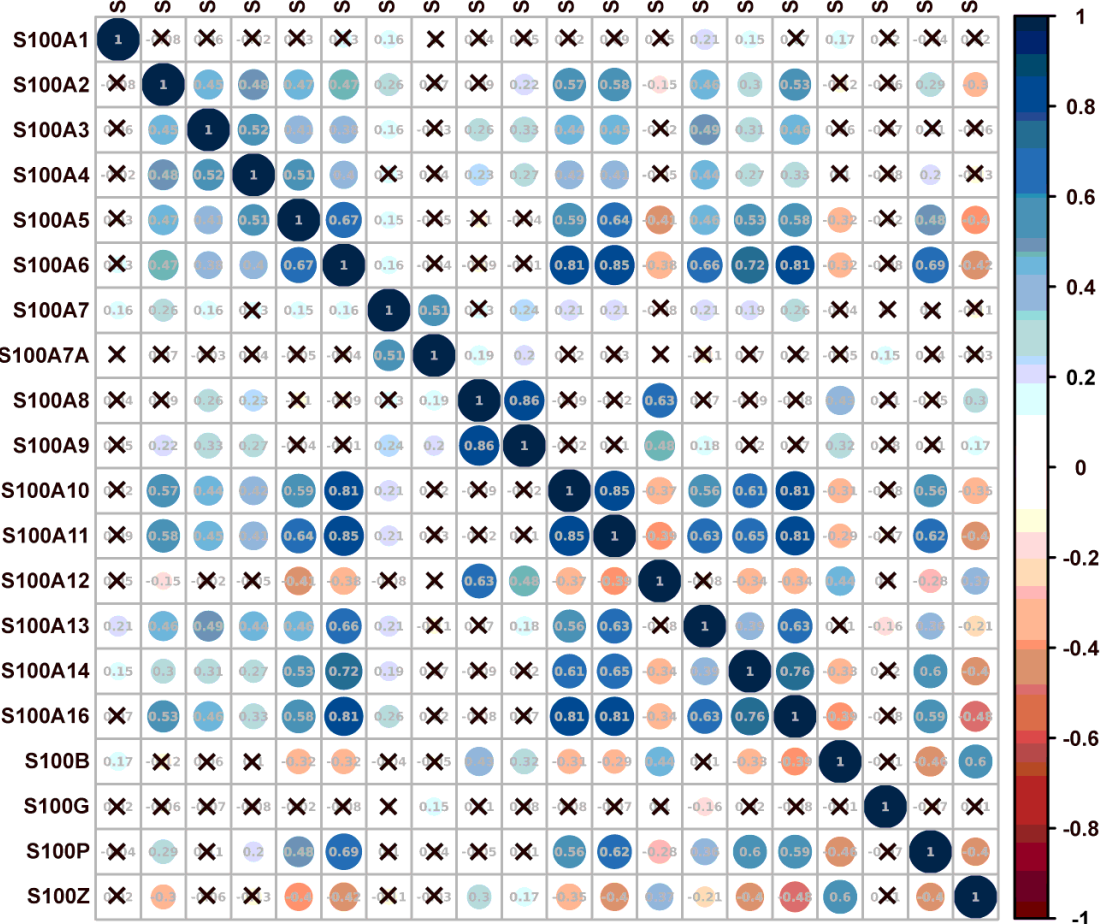

b

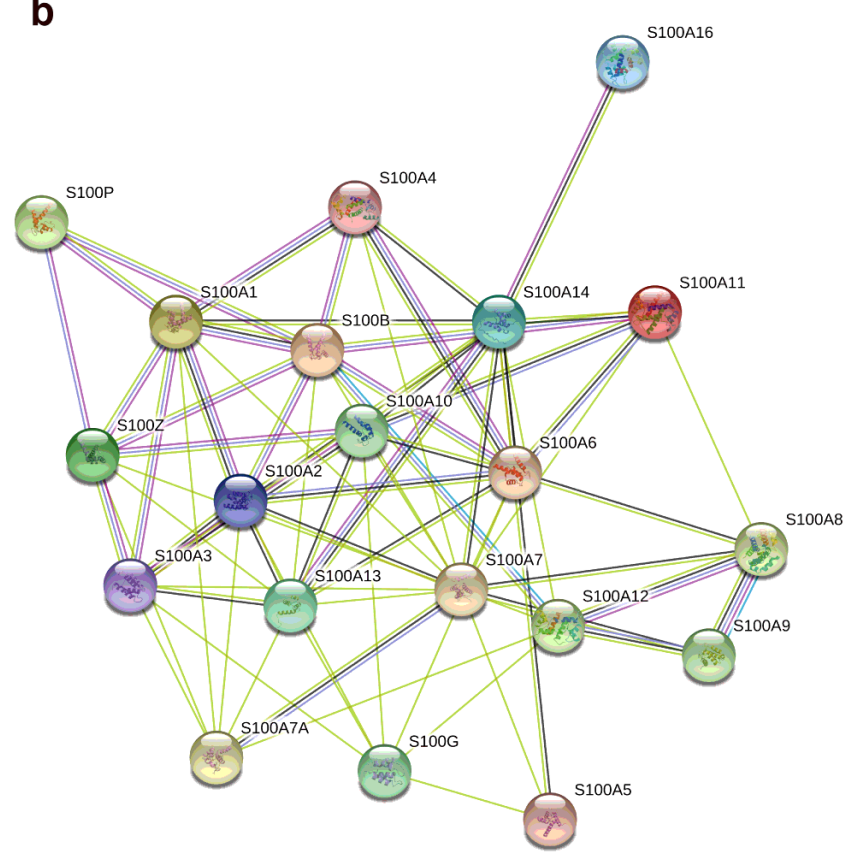

C

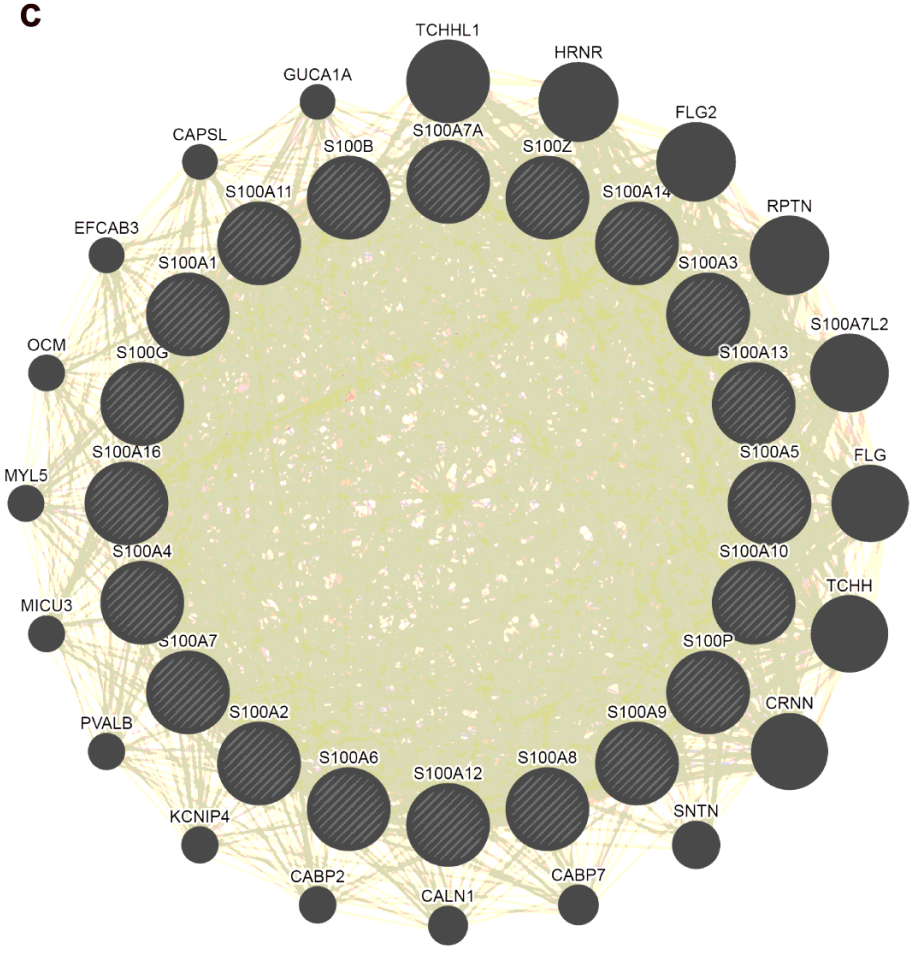

\section{Figure 7}

Co-expression, PPI and gene-gene network of S100s in PAAD patients. (a) Pearson's correlation coefficient of S100s(cBioPortal). (b) PPI network of S100s(STRING). (c) Gene-gene interaction network of S100s(GeneMANIA). 


\section{a}

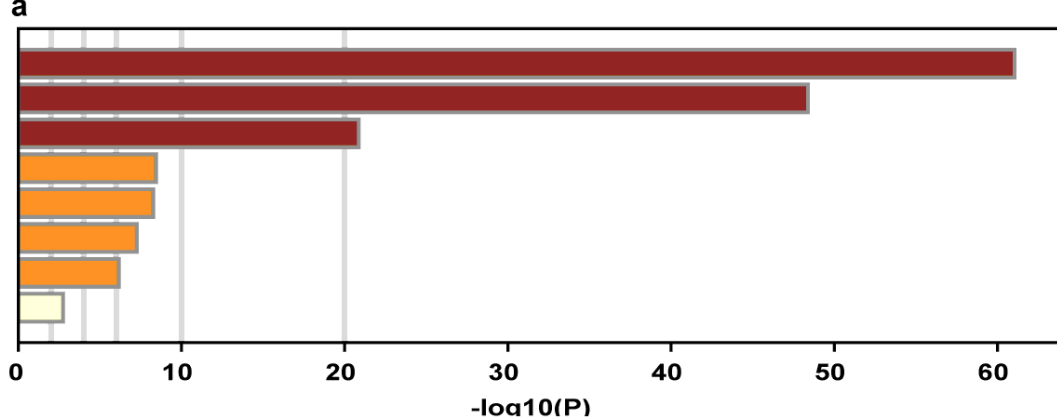

b
C

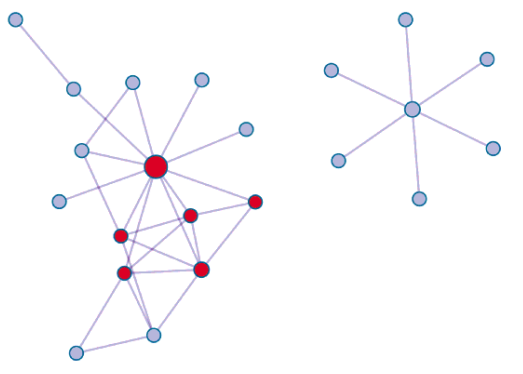

GO:0005509: calcium ion binding GO:0048306: calcium-dependent protein binding GO:0050786: RAGE receptor binding GO:0044548: S100 protein binding GO:0001533: cornified envelope GO:0043299: leukocyte degranulation GO:0048471: perinuclear region of cytoplasm GO:0010038: response to metal ion

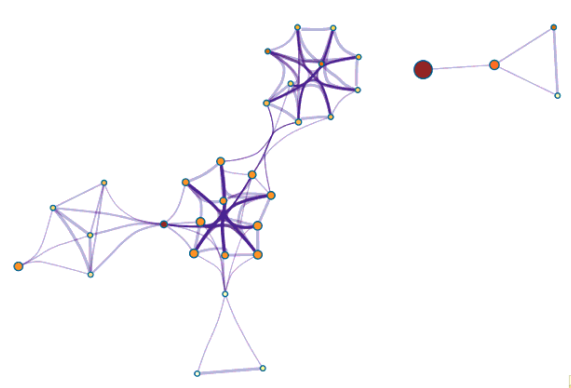

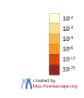
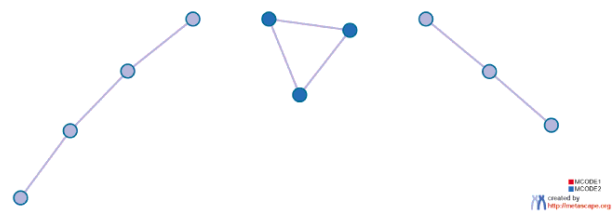

d

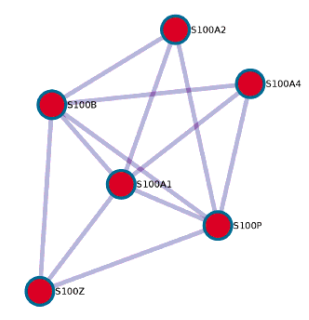

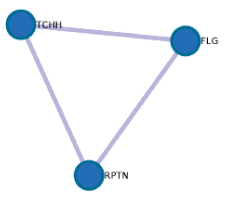

e

\begin{tabular}{clllc} 
Color & MCODE & GO & Description & Log10(P) \\
\hline & MCODE_1 & GO:0048306 & calcium-dependent protein binding & -15.2 \\
\hline MCODE_1 & GO:0005509 & calcium ion binding & -9.6 \\
\hline MCODE_1 & GO:0042803 & protein homodimerization activity & -5.3 \\
\hline MCODE_2 & GO:0001533 & cornified envelope & -8.4 \\
\hline MCODE_2 & GO:0070268 & cornification & -7.2 \\
\hline MCODE_2 & GO:0031424 & keratinization & -6.3 \\
\hline
\end{tabular}

\section{Figure 8}

The enrichment analysis of S100s and the co-expression genes in PAAD patients(Matascape). (a) Histogram of the top 8 enriched terms. (b) enriched terms network, colored by $p$-value. (c-e) PPI network and MCODE components 

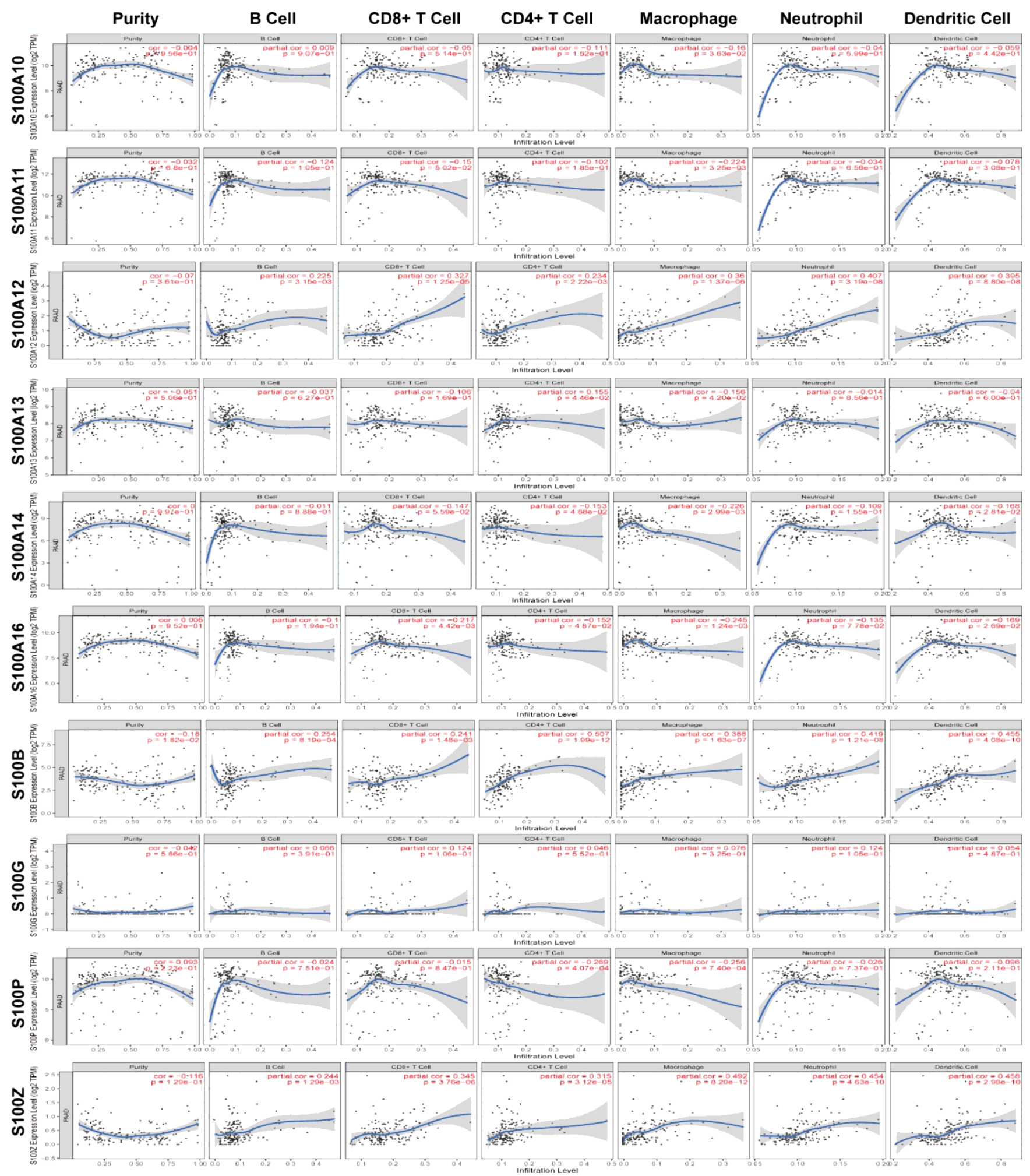

\section{Figure 9}

The association between S100s and Tumor-Infiltrating Immune Cells in PAAD patients(TIMER 2.0). 